\title{
Légua \&Meia
}

\author{
$\underline{\text { Revista deLiteratura }}$
}

e Diversidade Cultural 


\section{Légua \& Meia}

R evista de Literatura e

Diversidade Cultural

ISSN 1676-5095

Ano 15, no $8-2017$

\section{Editores:}

Cláudio Cledson Novaes

Flávia Aninger de Barros Rocha

Patrício Nunes Barreiros

\section{Secretária:}

Joelma Trajano

\section{Conselho Editorial:}

Aleilton Santana da Fonseca (UEFS)

Álvaro Santos Simões Júnior (UNESP)

Eduardo de Faria Coutinho (UFRJ)

Francisco Ferreira de Lima (UEFS)

Jorge de Souza Araújo (UEFS)

Patrícia Kátia da Costa Pina (UNEB) Regina Zilberman (UFRGS)

Ricardo Tupiniquim Ramos (UNEB)

Roland Gerhard Mike Walter (UFPE)

Rubens Edson Alves Pereira (UEFS)

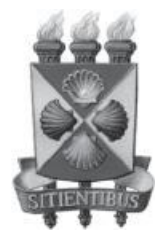

Programa de Pós-graduação em Estudos Literários - PROGEL Universidade

Estadual de Feira de Santana

Campus Universitário, Módulo 2 - Prédio de Pós-graduação em Educação, Letras e Artes 44036-900

- Caixa Postal 252 - Feira de Santana - Bahia

E-mail:posldc@uefs.br-Fone: (75) 3161-8863 www.uefs.br/posldc 
ISSN 1676-5095

\section{Légua\&Meia Revista de Literatura e Diversidade Cultural}

Ano 15, no $8-2017$ 
Légua \& Meia é uma publicação

Do ProgramadePós-Graduação em Estudos Literários da

Universidade EstadualdeFeira de Santana

\section{Organização:}

Claudio Cledson Novaes

Suênio Campos de Lucena

Flávia Aninger de Barros Rocha

\section{Dossiê fotográfico:}

Aleilton Fonseca

\section{FICHA CATALOGRÁFICA}

Légua\& Meia:Revista deliteratura ediversidadecultural.Programa dePós-GraduaçãoemEstudosLiterários-PROGEL - vol.1,n.1(2001 - ). - FeiradeSantana:UEFS, 2001v.: il.

ISSN 1676-5095

Ano 15, nº 8, 2017.

1. Literatura - Periódica. 2. DiversidadeCultural - Periódicos. I Programa dePós-Graduação em Estudos Literários - Progel. II. Universidade Estadual de Feira deSantana.

CDD: 869.9

CDU: $869.0(81)$

IMPRESSO NO BRASIL 